\title{
Psychological Demand
}

National Cancer Institute

\section{Source}

National Cancer Institute. Psychological Demand. NCI Thesaurus. Code C92459.

The mental arousal or stimulation necessary to accomplish a task. 